\title{
Postoperative complications and short-term oncological outcomes of patients aged $\geq 80$ years undergoing robot-assisted radical cystectomy
}

\author{
Daniel P. Nguyen • Bashir Al Hussein Al Awamlh • \\ E. Charles Osterberg · James Chrystal · Thomas Flynn • \\ Daniel J. Lee · Douglas S. Scherr
}

Received: 28 August 2014 / Accepted: 12 November 2014 / Published online: 20 November 2014

(C) Springer-Verlag Berlin Heidelberg 2014

\begin{abstract}
Purpose To assess complication rates and early oncological outcomes of patients aged $\geq 80$ years who underwent robot-assisted radical cystectomy (RARC).

Methods A total of 368 consecutive patients underwent radical cystectomy from April 2001 to September 2013 in a tertiary referral center. Sixty-one patients aged $\geq 80$ years underwent RARC and constitute the cohort of interest. Complications arising within 30 and 90 days of surgery were graded using the modified Clavien classification and were additionally categorized by organ system using a standardized complication reporting system. Recurrencefree survival, disease-specific survival and overall survival were calculated using Kaplan-Meier curves.

Results Median age was 83 years (range 80-94). Twentynine $(48 \%)$ of all tumor specimens were stage $\geq$ pT3. The median number of nodes removed was 19 (range 6-67). The soft tissue positive margin rate was $10 \%$. A total of $27(44 \%)$ patients had complications within 90 days, of which 9 had major complications. Two patients (3\%) died from surgical complications within 90 days. At a median follow-up of 13 months, 12 (20\%) patients had developed recurrent cancer and subsequently died from disease. An additional $13(21 \%)$ patients died from non-cancer-related causes. The median overall survival time was 36.0 months.
\end{abstract}

D. P. Nguyen $(\bowtie) \cdot$ B. A. H. A. Awamlh · E. Charles Osterberg ·

J. Chrystal · T. Flynn · D. J. Lee · D. S. Scherr

Department of Urology, Weill Cornell Medical College, New

York Presbyterian Hospital, 525 E 68th St, New York, NY 10021,

USA

e-mail: danielphatnguyen@ @otmail.com

D. P. Nguyen

Department of Urology, Berne University Hospital, Berne,

Switzerland
At 2 years, recurrence-free, cancer-specific and overall survival rates were 73,74 and $61 \%$, respectively.

Conclusions In patients aged $\geq 80$ years, RARC is feasible with acceptable perioperative morbidity and favorable short-term oncological outcomes. Therefore, RARC should be considered a valid option for carefully selected patients aged $\geq 80$ years with bladder cancer.

Keywords Bladder cancer - Complications · Octogenarians · Robot-assisted radical cystectomy · Survival

\section{Introduction}

With the growth of an aging population in the years ahead, there is still a lack of consensus regarding the management of older patients with BCa [1]. Despite its indisputable value in selected patients [2-6], open radical cystectomy (RC) is associated with a significant risk for major complications and perioperative mortality in patients aged $\geq 80$ years $[2,5,7-10]$.

In an effort to improve perioperative outcomes without compromising oncologic efficacy, robot-assisted radical cystectomy (RARC) has gained increasing interest in recent years. Potential advantages of RARC include decreased intraoperative blood loss, reduced analgesic requirements and early ambulation [11], which may be particularly valuable in older patients. The early evidence indicates that comparable results can be achieved with open RC and RARC in terms of surgical efficacy, as assessed by positive surgical margin (PSM) rates and lymph node yield [11-13].

To date, the potential benefits of RARC in patients aged $\geq 80$ years have not been well described [14]. To redress 
this deficiency, we identified a cohort of patients aged $\geq 80$ years who underwent RARC and assessed perioperative complications using a standardized method of reporting [15-17]. In addition, short-term (2 years) oncological outcomes were evaluated.

\section{Materials and methods}

\section{Patient population}

Upon study approval by the Institutional Review Board, data on 368 consecutive patients who underwent RC from April 2001 and September 2013 were reviewed. The authors complied with the Declaration of Helsinki regarding ethical conduct in research involving human subjects. Of all, $79(19 \%)$ patients were aged $\geq 80$ years at the time of surgery. A total of $61(77 \%)$ of these 79 patients underwent RARC and constitute the cohort of interest. All RARCs were performed by one single surgeon (D.S.S.), using previously described technique [18]. Limits of the bilateral pelvic lymph node dissection were the upper common iliac artery superiorly, Cooper's ligament (including the node of Cloquet) inferiorly, the genitofemoral nerve laterally and the sacral promontory medially. Urinary diversion was performed extracorporeally [11]. An orogastric tube is inserted for surgery, then removed before the patient awakens. Placement of a naso-gastric tube is not routinely performed perioperatively.

\section{Outcomes measures}

\section{Complications}

All complications within 30 and 90 days were collected prospectively, using a standardized complication reporting system [15-17]. Regular correspondence with patients and their physician ensured that treatment received outside of our institution was accounted for in our database. All complications were graded using the modified Clavien classification system [15]. Grade 1 and Grade 2 complications were defined as minor, and Grade 3-5 complications were defined as major. Additionally, all complications were categorized by organ system $[11,17]$. Of note, ileus was defined as the inability to pass flatus $\geq 5$ days or to otherwise tolerate an oral diet (e.g., nausea/emesis, abdominal distension) and requiring naso-gastric tube.

\section{Oncologic outcomes}

Patient follow-up was offered every 3-4 months the first year, semi-annually for the second year, and annually thereafter. Diagnostic imaging was performed at least annually or when clinically indicated. For patients who died during the duration of the study, the cause of death was determined by the investigators through review of medical records or death certificates.

Statistical analysis

Adjusted odds ratios (OR) and $95 \%$ confidence intervals (CI) were calculated to assess predictors of both overall and major complications. Potential confounders included in multivariable analyses were patient's age at RARC (continuous), gender, body mass index (BMI; continuous), American Society of Anesthesiologists (ASA) score (2 vs $>2$ ), Charlson Comorbidity Index (CCI; 2 vs $>2$ ), prior surgery/ radiation, total operative time (continuous) and estimated blood loss (EBL) (continuous). Because ASA score and CCI were not collinear in our model (variance inflation factor $<2$ ), both comorbidity scores were considered. Recurrence-free survival, cancer-specific survival and overall survival were generated using the Kaplan-Meier method for the whole cohort and within subgroups stratified by tumor stage. Statistical significance was computed with the logrank test. All calculations were performed using IBM SPSS 21 (IBM, Armonk, NY, USA). A two-sided $p$ value $<0.05$ was considered significant.

\section{Results}

Baseline and pathologic data

Median age was 83 years (range 80-94) (Table 1). Twentynine $(48 \%)$ of all tumor specimens were stage $\geq$ pT3. Lymph node dissection was omitted in two patients with bulky $\mathrm{T} 4$ disease who underwent palliative cystectomies because of intractable symptoms and in one patient who had scarred tissue after radiation. Nodal stage could not be determined after review of the pathology report in one patient. In the remaining 57 patients, the median number of nodes removed was 19 (range 6-67). Soft tissue PSM was found in $6(10 \%)$ patients. Specifically, five (19\%) of 27 patients with $\geq$ pT3 disease had PSM, of whom four ( $80 \%$ ) had N2 stage, while one patient with T2 N0 disease had a PSM.

\section{Complications}

A total of 47 complications occurred in 27 patients within 90 days of surgery (Table 2). Within 30 days of surgery, 24 (75\%) of 32 complications were minor and eight $(25 \%)$ were major. Within 90 days of surgery, 35 (74\%) of 47 complications were minor and $12(26 \%)$ were major. Infectious complications were by far the most common 
Table 1 Baseline characteristics of patients aged $\geq 80$ years undergoing robot-assisted radical cystectomy

\begin{tabular}{|c|c|}
\hline & Patients $(n=61)$ \\
\hline Age [median (range)] & $83(80-94)$ \\
\hline \multicolumn{2}{|l|}{ Gender $[n(\%)]$} \\
\hline Male & $54(89)$ \\
\hline Female & $7(11)$ \\
\hline \multicolumn{2}{|l|}{ Ethnic origin } \\
\hline White $(\%)$ & $51(84)$ \\
\hline Black (\%) & $2(3)$ \\
\hline Asian $(\%)$ & $5(8)$ \\
\hline Other $(\%)$ & $3(5)$ \\
\hline BMI in $\mathrm{kg} / \mathrm{m}^{2}$ [median (IQR)] & $25(17-47)$ \\
\hline \multicolumn{2}{|l|}{ History of smoking } \\
\hline Yes & $32(52)$ \\
\hline No & $29(48)$ \\
\hline \multicolumn{2}{|l|}{ ASA score } \\
\hline 2 & $18(30)$ \\
\hline 3 & $39(64)$ \\
\hline 4 & $4(7)$ \\
\hline \multicolumn{2}{|l|}{ CACI } \\
\hline 2 & $14(23)$ \\
\hline 3 & $19(31)$ \\
\hline 4 & $9(15)$ \\
\hline 5 & $11(18)$ \\
\hline 6 & $3(5)$ \\
\hline 7 & $4(7)$ \\
\hline 8 & $1(2)$ \\
\hline \multicolumn{2}{|l|}{ Previous abdominal surgery } \\
\hline Yes & $20(33)$ \\
\hline No & $41(67)$ \\
\hline \multicolumn{2}{|l|}{ Previous radiotherapy } \\
\hline Yes & $13(21)$ \\
\hline No & $48(79)$ \\
\hline \multicolumn{2}{|l|}{ Type of urinary diversion } \\
\hline Ileal conduit & $58(95)$ \\
\hline Indiana pouch & $2(3)$ \\
\hline Continent reservoir with appendix & $1(2)$ \\
\hline \multicolumn{2}{|l|}{ Neoadjuvant chemotherapy } \\
\hline No & $56(92)$ \\
\hline Yes, complete responder & $1(2)$ \\
\hline Yes, partial responder & $3(5)$ \\
\hline Yes, non-responder & $1(2)$ \\
\hline \multicolumn{2}{|l|}{ Histologic type } \\
\hline $\mathrm{TCC}$ & $59(97)$ \\
\hline Small cell carcinoma & $2(3)$ \\
\hline \multicolumn{2}{|l|}{ Pathologic stage $[n(\%)]$} \\
\hline pT0 & $2(3)$ \\
\hline pTa & $4(7)$ \\
\hline pTcis & $7(11)$ \\
\hline pT1 & $6(10)$ \\
\hline
\end{tabular}

Table 1 continued

\begin{tabular}{|c|c|}
\hline & Patients $(n=61)$ \\
\hline pT2 & $13(21)$ \\
\hline pT3 & $20(33)$ \\
\hline pT4 & $9(15)$ \\
\hline \multicolumn{2}{|l|}{ Lymphovascular invasion } \\
\hline Yes & $18(30)$ \\
\hline No & $43(70)$ \\
\hline \multicolumn{2}{|l|}{ Concomitant CIS $^{\mathrm{a}}$} \\
\hline Yes & $30(49)$ \\
\hline No & $24(39)$ \\
\hline \multicolumn{2}{|l|}{ Soft tissue positive margin } \\
\hline Yes & $6(10)^{\mathrm{b}}$ \\
\hline No & $53(90)$ \\
\hline \multicolumn{2}{|l|}{ LND performed } \\
\hline Yes & $58(95)$ \\
\hline No & $3(5)$ \\
\hline $\begin{array}{l}\text { Number of lymph nodes removed in case of LND } \\
\text { [median (range)] }\end{array}$ & $19(6-67)$ \\
\hline \multicolumn{2}{|l|}{ Nodal stage $[n(\%)]$} \\
\hline $\mathrm{pNx}$ & $4(7)$ \\
\hline pNO & 47 (77) \\
\hline pN1 & $2(3)$ \\
\hline $\mathrm{pN} 2$ & $8(13)$ \\
\hline \multicolumn{2}{|l|}{ Adjuvant chemotherapy } \\
\hline Yes & $2(3)$ \\
\hline No & $59(97)$ \\
\hline
\end{tabular}

$B M I$ body mass index, ASA American Society of Anesthesiologists, $C C I$ Charlson Comorbidity Index, $C I S$ carcinoma in situ, $L N D$ lymph node dissection, percentages may not sum to $100 \%$ due to rounding

a Not including patients with Tcis only in bladder specimen

b Not including two patients with bulky T4 disease who received palliative cystectomies without pelvic lymph node dissection

complication (38\%), followed by gastrointestinal and cardiac complications. No patient died from complications within 30 days of surgery. Two patients ( $3 \%$ ) died from surgical complications within 90 days, one patient from infectious complications (abdominal abscess) and another one from complications following a small bowel leak.

In a logistic regression model, patient's age at RARC, gender, BMI, prior surgery/radiation, ASA score (2 vs $>2$ ), CCI ( 2 vs $>2)$, operative time and EBL were not found to be independent predictors for any complication or major complications (all $p$ values $>0.05$ ).

Oncologic outcomes

Mean and median follow-up for surviving patients were 23 and 16 months, respectively ( $\mathrm{SD} \pm 21$; range $1-81$ ). At last follow-up, $36(59 \%)$ patients were alive without evidence of disease. Specifically, 22 (36\%) patients with follow-up 
greater than 12 months and $13(21 \%)$ patients with followup greater than 24 months were alive without evidence of disease at last follow-up. Twelve $(20 \%)$ patients, all with pathological stage $\geq \mathrm{pT} 3$, developed recurrent disease and subsequently died from disease. Median time to recurrence was 5 months (range 1-17). No port-site recurrence was documented. None of the patients with stage $\leq$ pT2 developed disease recurrence after mean and median follow-up intervals of 25 and 18 months, respectively ( $\mathrm{SD} \pm 21.7$; range $1-81)$. In addition, 13 (21\%) patients died from noncancer-related causes, for an overall mortality rate of $41 \%$.

Kaplan-Meier survival curves are depicted in Fig. 1. Median overall survival time was 36.0 months $(95 \%$ CI 29.6-42.4). At 1 and 2 years, the actuarial recurrence-free survival rates were 82 and $73 \%$, respectively, the actuarial cancer-specific-survival rates were 85 and $74 \%$, respectively, and the actuarial overall survival rates were 73 and $61 \%$, respectively. Stratification of survival outcomes by tumor stage showed significantly lower survival rates with increasing pathologic stage (all $p<0.0001$ ). Median overall survival times were 47.0 months (95\% CI 17.0-48.7) for stage T2, 15 months (95\% CI 13.2-27.0) for stage T3 and 6.0 months (95\% CI 3.8-16.5) for stage T4.

\section{Discussion}

The current study demonstrates that less than half (44\%) of all patients aged $\geq 80$ years undergoing RARC for $\mathrm{BCa}$ suffer complications within 90 days. After a median follow-up of 16 months, $59 \%$ of patients are alive without evidence of disease. As the average life span increases and $\mathrm{BCa}$ management in older patients is expected to become a major challenge, we take the view that RARC may be an attractive option for selected patients aged $\geq 80$ years diagnosed with muscle-invasive or high-risk non-muscle-invasive $\mathrm{BCa}$.

Earlier reports on outcomes of RARC have included younger and healthier patients with lower disease burden and the absence of prior pelvic treatment (radiation, surgery) $[18,19]$, which reflects the expected selection bias when a new surgical technique is introduced. In recent years, as experience with RARC increased, a few authors have attempted to address the role of RARC in older patients. In a small series of 23 patients aged $\geq 80$ years undergoing cystectomy, a $34.8 \%$ complication rate within 90 days, with no mortality, was reported [14]. Less encouraging was the high PSM rate of $26 \%$, although it has to be noted that $70 \%$ of all patients were staged $\geq \mathrm{pT} 3$. Using lower cutoffs of 70 and 75 years, respectively, two other studies aimed to compare operative and complication outcomes of younger and older patients undergoing RARC and found no differences [20, 21]. However, such
Table 2 Distribution and detailed description of 30- and 90-day complications

\begin{tabular}{|c|c|c|}
\hline & \multicolumn{2}{|c|}{ Patients $(n=61)$} \\
\hline & 30 days & 90 days \\
\hline Patients with complications $[n(\%)]$ & $19(31)$ & $27(44)$ \\
\hline Patients with major complications [n (\%)] & $5(8)$ & $9(15)$ \\
\hline \multicolumn{3}{|l|}{ Highest grade of complications } \\
\hline Grade $0[n(\%)]$ & $42(69)$ & $34(56)$ \\
\hline Grade $1[n(\%)]$ & $2(3)$ & $3(5)$ \\
\hline Grade $2[n(\%)]$ & $12(20)$ & $15(25)$ \\
\hline Grade $3[n(\%)]$ & $4(7)$ & $5(8)$ \\
\hline Grade $4[n(\%)]$ & $1(2)$ & $2(3)$ \\
\hline Grade $5[n(\%)]$ & 0 & $2(3)$ \\
\hline Complications $(n)$ & 32 & 47 \\
\hline 1. Surgical & $1(3)$ & $1(2)$ \\
\hline Common bile duct injury & 1 & 1 \\
\hline 2. Wound & $2(6)$ & $2(4)$ \\
\hline Wound infection & 2 & 2 \\
\hline 3. Pulmonary & 0 & 0 \\
\hline 4. Neurologic & 0 & 0 \\
\hline 5. Genitourinary & $2(6)$ & $3(6)$ \\
\hline Acute renal failure & 1 & 1 \\
\hline Urinary retention & 1 & 1 \\
\hline Ureteral stricture & 0 & 1 \\
\hline 6. Infectious & $12(38)$ & $18(38)$ \\
\hline Fever of unknown origin & 2 & 2 \\
\hline Urinary tract infection & 3 & 4 \\
\hline Pyelonephritis & 1 & 1 \\
\hline Bacteremia/septicemia & 1 & 7 \\
\hline Abdominal abscess & 5 & 5 \\
\hline 7. Gastrointestinal & $4(13)$ & $9(19)$ \\
\hline Ileus & 3 & 3 \\
\hline Clostridium difficile & 1 & 3 \\
\hline Gastrointestinal bleeding & 0 & 1 \\
\hline Bowel leak & 0 & 2 \\
\hline 8. Cardiac & $5(16)$ & $6(13)$ \\
\hline Atrial fibrillation & 2 & 2 \\
\hline Supraventricular tachycardia & 2 & 2 \\
\hline Ventricular tachycardia & 1 & 2 \\
\hline 9. Bleeding & $3(9)$ & $3(6)$ \\
\hline Significant transfusion (>2 units) & 1 & 1 \\
\hline Hematoma & 1 & 1 \\
\hline Symptomatic anemia & 1 & 1 \\
\hline 10. Miscellaneous & $1(3)$ & $1(2)$ \\
\hline Oral candidiasis & 1 & 1 \\
\hline 11. Thromboembolic & $2(6)$ & $4(9)$ \\
\hline Deep venous thrombosis & 2 & 4 \\
\hline
\end{tabular}

Percentages may not sum to $100 \%$ due to rounding

comparative analyses are likely accompanied by bias in patient selection. Moreover, the first study was characterized by a particularly low number of patients with advanced 

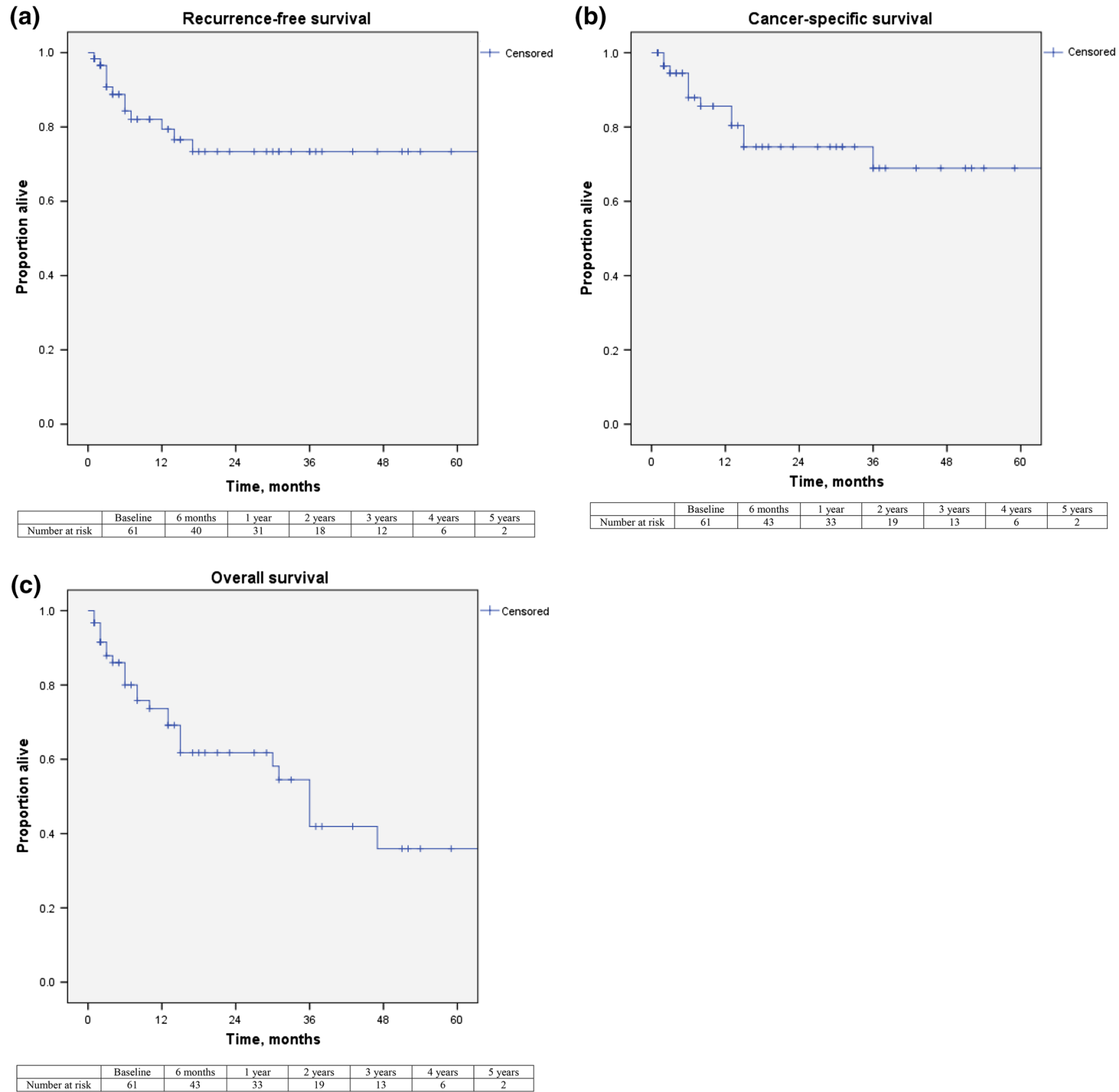

Fig. 1 Kaplan-Meier estimates of (a) recurrence-free, (b) cancer-specific and (c) overall survival probabilities in patients aged $\geq 80$ years who underwent robot-assisted radical cystectomy and pelvic lymph node dissection for bladder cancer

disease in both groups [20]. The three aforementioned studies reported complication rates of $34 \%$ within 30 days [20] and $34.8-45 \%$ within 90 days $[14,21]$. A major strength of the current study is the use of a standardized complication reporting system. Martin et al. [16] first established ten criteria that should be included when reporting complications. Subsequently, Shabsigh et al. [17] incorporated these recommendations into a complication reporting system for RC, which provided a model for the current and other recent studies evaluating RARC [11, 12, 22].
While the long-term oncologic outcomes of open RC in the general population have been well described [23], controversy exists regarding the benefit of surgery in patients aged $\geq 80$ years [1]. Three multicenter studies have shown that patients aged $\geq 80$ years are more likely to experience cancer recurrence and cancer-specific death than younger patients [3-5]. However, advanced age in these studies was also associated with higher pathological stage, lymphovascular invasion and positive PSMs [3-5], as well as pathological upstaging [3]. Survival analyses may thus have been 
influenced by longer delay between diagnosis and surgery and/or reluctance to offer RC, leading to a large group of older patients with more desperate cases referred to tertiary centers $[3,4]$. Conversely, another multicenter study found no difference in recurrence-free, cancer-specific and overall survival rates between age groups [6]. Although it is usually admitted that higher age is associated with higher rates of complications and perioperative mortality [7, 24], several open RC series have demonstrated that surgery nevertheless provides survival benefit in selected patients aged $\geq 80$ years [2-6]. Collectively, these conflicting data have led to the perception that elderly patients will not tolerate surgery because of age and/or comorbidity. In fact, a SEER study showed that only $16 \%$ of patients aged $80-84$ years and $4 \%$ of those aged $\geq 85$ years with muscle-invasive cancer undergo RC [25].

Evidence on long-term oncologic efficacy of RARC is still lacking. Surrogate markers for acceptable oncological outcome have been proposed by Herr et al. [26] and include a soft tissue PSM rate less than $10 \%$ and a lymph node yield greater than 10-14. Our median lymph node yield was 19 (range 6-67), and our soft tissue PSM rate was $10 \%$. PSM was more likely to occur in the setting of extravesical disease, as was the case in open RC series [27]. Therefore, our surgical technique is in line with these benchmark recommendations for quality of surgery. Although patient selection needs to be accounted for, our $74 \%$ cancer-specific and $61 \%$ overall survival rates at 2 years are in line or higher than numbers reported in open RC series evaluating patients aged $\geq 80$ years, with numbers ranging from 55 to $75 \%$ [3-6] and 50 to $60 \%$ [4-6], respectively. Although the follow-up interval is relatively short, our results were achieved despite the fact that $48 \%$ of all patients had extravesical disease, a proportion that is consistent with open RC series evaluating patients aged $\geq 80$ years $[2,3,5,6]$, and despite the fact that only $8 \%$ of patients received neoadjuvant chemotherapy.

In all, our findings argue that RARC is feasible and beneficial in patients aged $\geq 80$ years. However, as emphasized throughout this manuscript, the role of patient selection when evaluating a new surgical technique cannot be underappreciated. Our patients may have represented a selected group that despite high comorbidity profile had favorable factors that warranted the indication for the robotic approach. These factors include patient characteristics such as biological age, physical activity, oral anticoagulation, or tumor variables such as tumor size and local status. Nevertheless, the 61 patients in the current study represent $77 \%$ of all patients aged $\geq 80$ years that underwent $\mathrm{RC}$ at our institution, as our 10-year experience with RARC makes us comfortable offering this approach to the majority of older patients.

We acknowledge some limitations of our study. First, our study lacks a comparison cohort. We did not compare $\geq 80$ years RARC patients with $\geq 80$ years open RC patients because selection bias in favor of RARC would have been encountered. By the same token, comparison to a group of younger patients who underwent RARC would not have provided objective results. Outcomes of patients aged $\geq 80$ years should be evaluated in the context of agematched counterparts who did not undergo RC, ideally in a prospective, randomized trial. Due to our position as a tertiary referral center, it is also possible that we did not capture all complications that occurred after hospital discharge. Another limitation of our study is that it only reflects the experience of a single surgeon in a high-volume tertiary referral center.

These limitations notwithstanding, our study is the first to provide an accurate assessment of perioperative complications as well as short-term oncological outcomes in a large cohort of patients aged $\geq 80$ years. The 2 -year survival data are clinically useful when counseling patients aged $\geq 80$ years with $\mathrm{BCa}$, who have a life expectancy of 9.1 years in the USA (9.7 years for women, 8.2 years for men) [28].

\section{Conclusions}

RARC in patients aged $\geq 80$ years is associated with acceptable morbidity and favorable short-term oncological outcomes, suggesting that RARC duplicates the oncological principles of open $\mathrm{RC}$ in this group of patients. Therefore, RARC is a valid option for selected patients aged $\geq 80$ who are diagnosed with muscle-invasive, high-risk and recurrent non-muscle-invasive $\mathrm{BC}$.

Acknowledgments Daniel P. Nguyen is a research fellow and is supported by research grants from the Nuovo-Soldati, the Arnold U. und Susanne Huggenberger-Bischoff, the Bangerter Foundations and the Swiss Urological Association (Switzerland). Douglas S. Scherr's research work is supported in part by the Frederick $J$. and Theresa Dow Wallace Fund of the New York Community Trust.

Conflicts of interest The authors declare that they have no conflict of interest.

Ethical standard The creation and retrospective review of the Weill Cornell Medical College Bladder Cancer Database was approved by the Institutional Review Board of Weill Cornell Medical College and therefore conforms to the ethical standards laid down in the $1964 \mathrm{Hel}-$ sinki Declaration and its later amendments. No information with the potential to disclose patient identities was included.

\section{References}

1. Brausi MA, Whelan P (2007) The motion: radical cystectomy in the elderly is becoming a standard treatment for bladder cancer. Eur Urol 51:1435-1438. doi:10.1016/j.eururo.2007.02.008 
2. Donat SM, Siegrist T, Cronin A, Savage C, Milowsky MI, Herr HW (2010) Radical cystectomy in octogenarians-does morbidity outweigh the potential survival benefits? J Urol 183:21712177. doi:10.1016/j.juro.2010.02.015

3. Nielsen ME, Shariat SF, Karakiewicz PI, Lotan Y, Rogers CG, Amiel GE, Bastian PJ, Vazina A, Gupta A, Lerner SP, Sagalowsky AI, Schoenberg MP, Palapattu GS (2007) Advanced age is associated with poorer bladder cancer-specific survival in patients treated with radical cystectomy. Eur Urol 51:699-706. doi:10.1016/j.eururo.2006.11.004

4. Chromecki TF, Mauermann J, Cha EK, Svatek RS, Fajkovic H, Karakiewicz PI, Lotan Y, Tilki D, Bastian PJ, Volkmer BG, Montorsi F, Kassouf W, Novara G, Fritsche HM, Ficarra V, Stief CG, Dinney CP, Skinner E, Pummer K, Fradet Y, Shariat SF (2012) Multicenter validation of the prognostic value of patient age in patients treated with radical cystectomy. World J Urol 30:753759. doi:10.1007/s00345-011-0772-2

5. Fairey AS, Kassouf W, Aprikian AG, Chin JL, Izawa JI, Fradet Y, Lacombe L, Rendon RA, Bell D, Cagiannos I, Drachenberg DE, Lattouf JB, Estey EP (2012) Age $\geq 80$ years is independently associated with survival outcomes after radical cystectomy: results from the Canadian Bladder Cancer Network Database. Urol Oncol 30:825-832. doi:10.1016/j.urolonc.2011.07.014

6. Horovitz D, Turker P, Bostrom PJ, Mirtti T, Nurmi M, Kuk C, Kulkarni G, Fleshner NE, Finelli A, Jewett MA, Zlotta AR (2012) Does patient age affect survival after radical cystectomy? BJU Int 110(11 Pt B):E486-E493. doi:10.1111/j.1464-410X.2012.11180.x

7. Kuefer R, Gschwend JE, Bartsch GJ, Hautmann R, Volkmer BG (2006) Radical cystectomy in octogenarians. Eur Urol Suppl 5:290. doi:10.1016/S1569-9056(06)61072-5

8. Liberman D, Lughezzani G, Sun M, Alasker A, Thuret R, Abdollah F, Budaus L, Widmer H, Graefen M, Montorsi F, Shariat SF, Perrotte P, Karakiewicz PI (2001) Perioperative mortality is significantly greater in septuagenarian and octogenarian patients treated with radical cystectomy for urothelial carcinoma of the bladder. Urology 77:660-666. doi:10.1016/j.urology.2010.07.537

9. Berger I, Martini T, Wehrberger C, Comploj E, Ponholzer A, Wolfgang M, Breinl E, Dunzinger M, Hofbauer J, Höltl W, Jeschke K, Krause S, Kugler W, Pauer W, Rauchenwald M, Pycha A, Madersbacher S (2014) Perioperative complications and 90-day mortality of radical cystectomy in the elderly (75+): a retrospective, multicentre study. Urol Int Epub ahead of print

10. Froehner M, Brausi MA, Herr HW, Muto G, Studer UE (2009) Complications following radical cystectomy for bladder cancer in the elderly. Eur Urol 56:443-454. doi:10.1016/j.eururo.2009.05.008

11. Ng CK, Kauffman EC, Lee MM, Otto BJ, Portnoff A, Ehrlich JR, Schwartz MJ, Wang GJ, Scherr DS (2010) A comparison of postoperative complications in open versus robotic cystectomy. Eur Urol 57:274-281. doi:10.1016/j.eururo.2009.06.001

12. Johar RS, Hayn MH, Stegemann AP, Ahmed K, Agarwal P, Balbay MD, Hemal A, Kibel AS, Muhletaler F, Nepple K, Pattaras JG, Peabody JO, Palou Redorta J, Rha KH, Richstone L, Saar M, Schanne F, Scherr DS, Siemer S, Stökle M, Weizer A, Wiklund P, Wilson T, Woods M, Yuh B, Guru KA (2013) Complications after robot-assisted radical cystectomy: results from the International Robotic Cystectomy Consortium. Eur Urol 64:52-57. doi:10.1016/j.eururo.2013.01.010

13. Collins JW, Tyritzis S, Nyberg T, Schumacher M, Laurin O, Khazaeli D, Adding C, Jonsson MN, Hosseini A, Wiklund NP (2013) Robot-assisted radical cystectomy: description of an evolved approach to radical cystectomy. Eur Urol 64:654-663. doi:10.1016/j.eururo.2013.05.020
14. Phillips EA, Uberoi V, Tuerk IA (2014) Robot-assisted radical cystectomy in octogenarians. J Endourol 28:219-223. doi:10.1089/end.2013.0159

15. Dindo D, Demartines N, Clavien PA (2004) Classification of surgical complications. Ann Surg 240:205-213. doi:10.1097/01.sla. 0000133083.54934.ae

16. Martin RC 2nd, Brennan MF, Jaques DP (2002) Quality of complication reporting in the surgical literature. Ann Surg 235:803-813

17. Shabsigh A, Korets R, Vora KC, Brooks CM, Cronin AM, Savage C, Raj G, Bochner BH, Dalbagni G, Herr HW, Donat SM (2009) Defining early morbidity of radical cystectomy for patients with bladder cancer using a standardized reporting methodology. Eur Urol 55:164-174. doi:10.1016/j.eururo.2008.07.031

18. Wang GJ, Barocas DA, Raman JD, Scherr DS (2008) Robotic vs open radical cystectomy: prospective comparison of perioperative outcomes and pathological measures of early oncological efficacy. BJU Int 101:89-93. doi:10.1111/j.1464-410X.2007.07212.x

19. Murphy DG, Challacombe BJ, Elhage O, Elhage O, O'Brien TS, Rimington P, Khan MS, Dasgupta P (2008) Roboticassisted laparoscopic radical cystectomy with extracorporeal urinary diversion: initial experience. Eur Urol 54:570-580. doi:10.1016/j.eururo.2008.04.011

20. Coward RM, Smith A, Raynor M, Nielsen M, Wallen EM, Pruthi RS (2011) Feasibility and outcomes of robotic-assisted laparoscopic radical cystectomy for bladder cancer in older patients. Urology 77(5):1111-1114. doi:10.1016/j.urology.2010.07.510

21. Richards KA, Kader AK, Otto R, Pettus JA, Smith JJ, Hemal AK (2012) Is robot-assisted radical cystectomy justified in the elderly? A comparison of robotic versus open radical cystectomy for bladder cancer in elderly $\geq 75$ years old. J Endourol 26:13011306. doi:10.1089/end.2012.0035

22. Hayn MH, Hellenthal NJ, Hussain A, Stegemann AP, Guru KA (2011) Defining morbidity of robot-assisted radical cystectomy using a standardized reporting methodology. Eur Urol 59:213218. doi:10.1016/j.eururo.2010.10.044

23. Zehnder P, Studer UE, Skinner EC, Thalmann GN, Miranda G, Roth B, Cai J, Birkhäuser FD, Mitra AP, Burkhard FC, Dorin RP, Daneshmand S, Skinner DG, Gill IS (2013) Unaltered oncological outcomes of radical cystectomy with extended lymphadenectomy over three decades. BJU Int 112:E51-E58. doi:10.1111/bju.12215

24. Clark PE, Stein JP, Groshen SG, Cai J, Miranda G, Lieskovsky G, Skinner DG (2005) Radical cystectomy in the elderly: comparison of clinical outcomes between younger and older patients. Cancer 104:36-43. doi:10.1002/cncr.21126

25. Prout GR Jr, Wesley MN, Yancik R, Ries LA, Havlik RJ, Edwards BK (2005) Age and comorbidity impact surgical therapy in older bladder carcinoma patients: a population-based study. Cancer 104:1638-1647. doi:10.1002/cncr.21354

26. Herr H, Lee C, Chang S, Lerner S (2004) Standardization of radical cystectomy and pelvic lymph node dissection for bladder cancer: a collaborative group report. J Urol 171:1823-1828. doi:10.1 097/01.ju.0000120289.78049.0e

27. Dotan ZA, Kavanagh K, Yossepowitch O, Kaag M, Olgac S, Donat M, Herr HW (2007) Positive surgical margins in soft tissue following radical cystectomy for bladder cancer and cancer specific survival. J Urol 178:2308-2312. doi:10.1016/j.juro.2007.08.023

28. Arias E (2014) United States life tables, 2009. Natl Vital Stat Rep 62:1-63 